\title{
Single-Dose Bioequivalence of a New Fixed-Dose Combination Tablet Containing Tenofovir Disoproxil Fumarate and Lamivudine
}

\author{
Feleder Ethel $C^{1 *}$, Yerino Gustavo A ${ }^{1}$, Halabe Emilia K ${ }^{1}$, Carla Serebrinsky², Soledad Gonzalez ${ }^{2}$ and Zini Elvira $^{2}$
}

${ }^{1}$ F.P. Clinical Pharma, Buenos Aires, Argentina

${ }^{2}$ Richmond Laboratories, Buenos Aires, Argentina

\begin{abstract}
Tenofovir Disoproxil Fumarate, CAS 147127-20-6 is a nucleotide reverse transcriptase inhibitor with potent activity against both HIV and hepatitis B infections. Lamivudine, CAS 134678-17-4 is a nucleoside analogue reverse transcriptase inhibitor developed as a treatment for HIV infection and also with activity against hepatitis $B$ virus. The combination of tenofovir and lamivudine associated either with non-nucleoside reverse transcriptase inhibitors or with a ritonavir-boosted or unboosted protease inhibitor are recommended as preferred regimens for antiretroviral therapy-naïve patients infected with HIV, and also for the treatment of HIV-HVB coinfected patients. The objective of this study was to compare rate and extent of absorption and to assess the bioequivalence between a new pharmaceutical equivalent tablet formulation containing a fixed-dose combination of tenofovir disoproxil fumarate/ lamivudine $300 / 300 \mathrm{mg}$ and the innovator products. A randomized, single-center, open-label, single-dose, two-way crossover bioequivalence study in 40 healthy adult subjects was conducted. Dosing was separated by a wash-out period of 14 days. All subjects signed an informed consent form. In each study period, 13 blood samples were collected in Vacutainers containing EDTA over $48 \mathrm{~h}$. Plasma levels of tenofovir and lamivudine were determined by a validated HPLC/fluorescence assay and by a validated HPLC/UV assay, respectively. Rate and extent of absorption were similar between products. The $90 \%$ confidence interval $(\mathrm{Cl})$ of the ratio of the geometric means for log-transformed $\mathrm{C}_{\max }, \mathrm{AUC}_{\text {last }}$ and $\mathrm{AUC} \mathrm{C}_{\text {inf }}$ values were used to assess bioequivalence between the two formulations using the equivalence interval of 80 and $125 \%$. In healthy subjects, the point estimate and $90 \% \mathrm{C}$ of the ratios of $\mathrm{C}_{\text {max }}, \mathrm{AUC}_{\text {last }}$ and $A \cup \mathrm{C}_{\text {inf }}$ values for tenofovir were 100.99\%(92.89-109.80\%), 96.11\%(90.02-102.63\%) and $94.73 \%(88.22-101.73 \%)$, respectively; and for lamivudine were $90.37 \%(83.76-97.50 \%), 97.02 \%(93.27-100.93 \%)$ and $97.04 \%(93.41-100.82 \%)$, respectively. Both treatments exhibited similar tolerability and safety. It was concluded that the new pharmaceutical formulation was bioequivalent to the innovators.
\end{abstract}

Keywords: Bioequivalence; tenofovir; lamivudine; fixed-dose combination; healthy volunteers

\section{Introduction}

Tenofovir disoproxil fumarate (TDF) is a nucleotide analog reverse transcriptase inhibitor orally bioavailable as an ester-derived prodrug which requires diester hydrolysis for conversion to tenofovir (TFV) and subsequent intracellular phosphorylations by cellular enzymes to the active metabolite, tenofovir diphosphate, which is a competitive inhibitor of HIV-1 reverse transcriptase, leading to the prevention of DNA chain elongation and termination of viral DNA growth $[1,2]$. TDF was approved by the Food and Drug Administration (FDA) in October 2001 and is indicated for use in combination with other antiretroviral agents for the management of HIV-1 infection. TFV has also activity against hepatitis B infection and has been approved in 2009 as the firstline option in the treatment of hepatitis $B[3,4]$. The pharmacokinetic (PK) of TFV following oral administration of $300 \mathrm{mg}$ has been well characterized in HIV-infected and healthy adults subjects. After oral administration of $300 \mathrm{mg}$, TFV concentrations increase over 1 to $3 \mathrm{~h}$ $\left(\mathrm{T}_{\max }\right)$ with a maximum concentration $\left(\mathrm{C}_{\max }\right)$ of approximately $300 \mathrm{ng} /$ $\mathrm{ml}$ and a mean area under the plasma concentration-versus-time curve (AUC) at steady state of approximately $3000 \mathrm{ng} \mathrm{g}^{\star} \mathrm{h} / \mathrm{ml}$ is observed $[5,6]$. When administered with a high fat meal (700-1000 calories containing $40-50 \%$ fat), TFV AUC and Cmax are increased by $40 \%$ and $14 \%$, respectively. TFV is primarily cleared unchanged in the urine by a combination of glomerural filtration and active tubular secretion. The once-daily dosing schedule is supported by TFV serum elimination half-life of 12 to $17 \mathrm{~h}$ and the long half-life of the intracellular metabolite between 10 to $50 \mathrm{~h} \mathrm{[7]}$.

Lamivudine (3TC) is a nucleoside analogue developed as a treatment for HIV infection. It has also activity against hepatitis $B$ virus (HBV). Intracellular, lamivudine is phosphorylated to its active metabolite, lamivudine $5{ }^{\prime}$-triphosphate (3TC-TP) which prevents HIV-1 and HBV replication by competitively inhibiting viral reverse transcriptase via DNA chain termination after incorporation of the nucleotide analogue The pharmacokinetics of 3TC are similar in patients with HIV-1 or HVB infection, and healthy volunteers [8]. Following oral administration, 3TC is well absorbed from the gastrointestinal tract, being the bioavailability in adults between 80 and $85 \%$, and the mean time $\left(\mathrm{T}_{\mathrm{ma}}\right)$ to maximal serum concentrations $\left(\mathrm{C}_{\max }\right)$ about an hour. Based on data derived from a study in healthy volunteers, at a therapeutic dose of $150 \mathrm{mg}$ twice daily, mean steadystate $\mathrm{C}_{\max }$ and $12 \mathrm{~h} \mathrm{AUC} \mathrm{in} \mathrm{plasma} \mathrm{are} 1200 \mathrm{ng} / \mathrm{ml}$ and $4700 \mathrm{ng}{ }^{\star} \mathrm{h} /$ $\mathrm{ml}$, respectively. Lamivudine systemic exposure (based on the AUC) is not influenced when it is administered with food and is widely distributed into total body fluid being predominately eliminated

*Corresponding author: Ethel Carina Feleder, MD, PhD. F.P. Clinical Pharma, Juncal 4484, 3rd. floor, (CP1425) Buenos Aires, Argentina, Tel: 5411-4775-2640 Fax: 5411-4775-2869; E-mail: efeleder@fpclinicalpharma.com.ar, gyerino@ fpclinicalpharma.com.ar

Received October 24, 2011; Accepted November 21, 2011; Published November 23, 2011

Citation: Feleder EC, Yerino GA, Halabe EK, Carla S, Soledad G, et al. (2011) Single-Dose Bioequivalence of a New Fixed-Dose Combination Tablet Containing Tenofovir Disoproxil Fumarate and Lamivudine. J Bioequiv Availab 3: 236-243. doi:10.4172/jbb.1000093

Copyright: (c 2011 Feleder EC, et al. This is an open-access article distributed under the terms of the Creative Commons Attribution License, which permits unrestricted use, distribution, and reproduction in any medium, provided the original author and source are credited. 
unchanged by renal excretion. The dominant elimination half-life of 3TC is approximately 5 to $7 \mathrm{~h}$, and the intracellular in vitro half-life of its active 5 -triphosphate metabolite is approximately 10.5 to $15.5 \mathrm{~h} \mathrm{[9].}$

The Working Group of the Office of AIDS Research Advisory Council (OARAC) recommends the combination of 2NRTI (nucleoside reverse transcriptase inhibitors) such as TDF and 3TC associated either with a NNRTI (non-nucleoside reverse transcriptase inhibitors) such as efavirenz (EFV) or with a ritonavir-boosted or un-boosted PI (protease inhibitor) as the preferred regimens (AI) for antiretroviral therapy (ART)-naïve patients infected with HIV. Moreover, the combination of TDF and 3TC or FTC is recommended as the preferred regimen (AII) for the treatment of HIV-HVB co-infected patients [3].

Successful long-term treatment of HIV/AIDS requires high levels of patient's adherence to therapy to prevent drug-resistance that leads to treatment failure. Incomplete adherence to HIV regimens is associated to their complexity, frequency, discordant dosing schedules; therefore pharmaceutical strategies to simplify patient's adherence are significant determinants of treatment outcomes. A new oral tablet formulation containing a fixed-dose combination of TDF/3TC 300/300 $\mathrm{mg}$ has been developed to support OARAC recommendations for firstline therapy and to help improve patient compliance with once-daily dosing of this combination tablet. The objective of the present study was to evaluate and compare the rate and extent of absorption of both TDF and 3TC from the new combination dosage form related to that of the innovators single formulations in healthy volunteers under fasting conditions.

\section{Subjects and Methods}

\section{Study design and methodology}

A randomized, balanced, open-label, single-center, single-dose, two treatment, two period, two sequence, crossover bioequivalence study in 40 healthy adults subjects under fast condition was carried out. The study was conducted at FP Clinical Pharma Clinical-Pharmacokinetic Unit located at Buenos Aires, Argentina between September and December 2010. Both, the study protocol and the Informed Consent Form (ICF) were approved by an Institutional Review Board, an Independent Ethic Committee and by the local Regulatory Agency (ANMAT) before the beginning. Clinical procedures were carried out in accordance with ICH-GCP guidance, FDA guidance for conducting bioavailability and bioequivalence studies for oral administered drugs and the principles enunciated in the latest version of the Declaration of Helsinki [10-12]. All subjects who volunteered to participate signed an approved ICF.

All volunteers were randomly assigned to receive either a single $300 / 300 \mathrm{mg}$ of the new fixed-dose combination oral tablet of TDF/3TC Mivuten $^{\circledR}$ as test preparation (batch No.1344), manufactured by Richmond Laboratories, Buenos Aires, Argentina, or a single 300 $\mathrm{mg}$ oral tablet of the innovator product TDF: Viread ${ }^{\circledR}$ (batch No. L05847) manufactured by Gilead Sciences plus two single $150 \mathrm{mg}$ oral film-coated tablets of the innovator product 3TC: $3 \mathrm{TC}^{\circledR}$ (batch No. R397808-1) manufactured by GlaxoSmithKline as reference preparations. Both reference products were purchased at a local pharmacy. The treatments were administered under fasting condition in two different dosing periods separated by a 14-day wash-out period according to a predetermined randomized schedule. Subjects were not allowed to either crush or chew the study medication. Mouth checks were performed after each dosing. Subjects remained under fasting condition until after the 4-hour post-dosing. A standard lunch and afternoon meal were administered after the $4^{\text {th }}$ and $8^{\text {th }}$ hour of drug administration, respectively.

\section{Study population}

Sample size was calculated using the formula developed by Marzo and Balant, using $\mathrm{C}_{\max }$ CVs of $38 \%$ for TDF and of $24 \%$ for $3 \mathrm{TC}$, according to literature $[1,9,13]$. A total of 40 healthy male and female subjects (non-pregnant and non-lactating) between 21 and 50 years of age were enrolled. Inclusion criteria included Body Mass Index (BMI) between 19 and $27 \mathrm{Kg} / \mathrm{m}^{2}$. Female subjects of childbearing potential (ie. not surgically sterile or at least 2 years postmenopausal) were required to have a negative pregnancy test at screening and agree to use a highly effective contraception method (not hormonal) while on study treatment and for three weeks after the last dose of study drugs. Laboratory values, 12-lead electrocardiograms and chest $\mathrm{x}$-rays for all subjects had to be within normal range. Negative test for VIH, hepatitis $\mathrm{B}$ and $\mathrm{C}$ viruses were also required.

Subjects were excluded if they had a history of alcohol or drug abuse in the last two years, history or current manifestations of gastrointestinal disease or surgery, or hepatic, cardiovascular, respiratory, renal, hematopoietic, neurological, endocrine-metabolic diseases. Volunteers were not allowed to use any kind of medicine within the previous two weeks and throughout the study execution. Other standard exclusion criteria for $\mathrm{BD} / \mathrm{BE}$ studies were adopted for subject enrollment [11].

\section{Sample collection}

A total of 13 serial blood samples for pharmacokinetic assessments were collected by venipuncture over a $48 \mathrm{~h}$ period at the following points: 0 (pre-dose), $0.5,1,1.5,2,3,4,6,8,10,12,24$ and $48 \mathrm{~h}$ after oral administration of each treatment. For each sample, approximately $10 \mathrm{ml}$ of blood was collected into vacutainers containing EDTA as an anticoagulant. Blood samples were centrifuged and separated plasma was frozen at $-20^{\circ} \mathrm{C}$ until analysis.

\section{Bio analytical procedures}

Tenofovir concentrations in human plasma was determined by a validated HPLC/fluorescence method using an analytical column

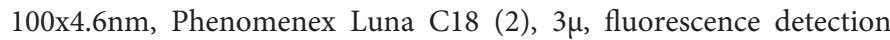
within 236 to $420 \mathrm{~nm}$. The lower limit of quantification (LOQ) corresponding to TFV was $5.0 \mathrm{ng} / \mathrm{ml}$. The relationship between concentration and peak area ratio for TDF (TFV: Internal Standard) was found to be linear within the range of $5.0 \mathrm{ng} / \mathrm{ml}$ to $1000.0 \mathrm{ng} / \mathrm{ml}$. The precision and accuracy in the assay validation were evaluated using 3 separate analytical runs, with each containing quality control samples in replicates of 5 . Inter- and intra-assay precision had a $<6 \%$ coefficient of variation.

Lamivudine concentrations in human plasma was determined by a validated HPLC/ UV method using an analytical column $75 \times 4.6$

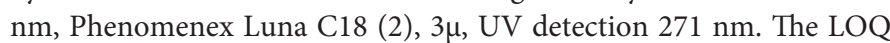
corresponding to $3 \mathrm{TC}$ was $20.0 \mathrm{ng} / \mathrm{ml}$. The relationship between concentration and peak area ratio (3TC: Internal Standard) was found to be linear within the range of $20.0 \mathrm{ng} / \mathrm{ml}$ to $4000.0 \mathrm{ng} / \mathrm{ml}$. The precision and accuracy in the assay validation were evaluated using 3 separate analytical runs, with each containing quality control samples in replicates of 5 . Inter- and intra assay precision had a $<3 \%$ coefficient of variation. 
Full methodological validation was carried out according to local and FDA guidance for bioanalytical method validation [14].

\section{In vitro dissolution}

The in vitro dissolution study of both tablets were studied in USP apparatus type II employing a paddle stirrer at $50 \mathrm{rpm}$ using $900 \mathrm{ml}$ of $0.1 \mathrm{~N} \mathrm{HCl}$ at $37 \pm 0.5^{\circ} \mathrm{C}$ as dissolution medium. The percentage of drug release was calculated using an equation obtained from a standard curve and results are presented in Figures 1A and 1B.

\section{Pharmacokinetic evaluation}

The plasma concentration-time data after oral administration of a single dose of test and reference products were analyzed using a Non-compartmental pharmacokinetic model (WinNonlin, version 5.3; Pharsight, Certara, USA). The maximum plasma concentration and the corresponding sampling time were defined as $\mathrm{C}_{\max }$ and $\mathrm{T}_{\max }$ ' respectively. The slope of the log-linear regression function $(\lambda)$ was the first order rate constant associated with the terminal portion of the curve estimated by linear regression of time vs. log-concentration. The elimination half-life $\left(\mathrm{T}_{1 / 2}\right)$ was estimated as $\ln 2 / \lambda$. The area under the plasma concentration-time curve from the time of dosing to the last measurable concentration $\left(\mathrm{AUC}_{\text {last }}\right)$ was calculated using the trapezoidal rule. The AUC from dosing time extrapolated to infinity based on the last observed concentration was defined as $\mathrm{AUC}_{\text {inf }}$. Which was calculated by the equation $\mathrm{AUC}_{\text {inf }}=\mathrm{AUC}+\left(\mathrm{C}_{\mathrm{n}} / \lambda\right)$ where $\mathrm{C}_{\mathrm{n}}$ is the last measurable concentration and $\lambda$ is the slope of the log-linear regression function. A pharmacokinetic rule was generated to treat data coming from samples presenting values less than the lower level of quantification in bio analytic assays.

\section{Safety assessment}

Physical examination, hematology, platelets count, serum
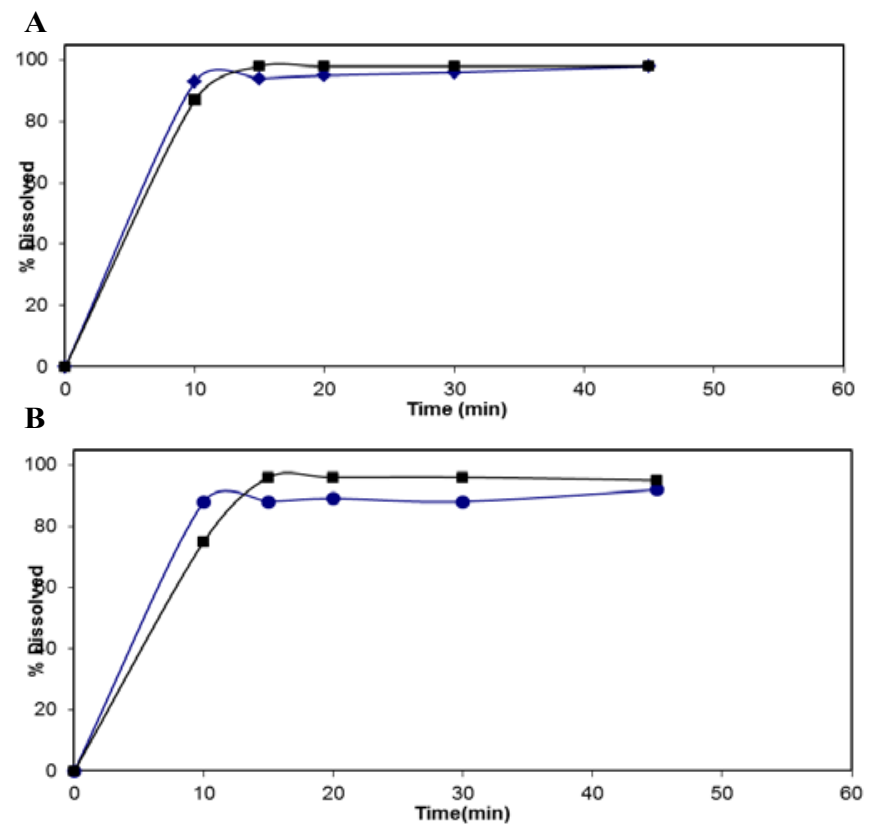

Figure 1: (A) In vitro dissolution profiles for lamivudine for Reference (square) and test (circle) products.

(B) In vitro dissolution profiles for tenofovir for Reference (square) and test (circle) products.

\begin{tabular}{|c|c|}
\hline Characteristic & $\begin{array}{c}\text { Results } \\
\text { (mean } \pm \text { SD) }\end{array}$ \\
\hline Age $(\mathrm{yrs})$ & $34.32 \pm 8.84$ \\
\hline Height $(\mathrm{cm})$ & $167.82 \pm 8.96$ \\
\hline Weight $(\mathrm{kg})$ & $69.89 \pm 10.33$ \\
\hline BMl $\left(\mathrm{kg} / \mathrm{m}^{2}\right)$ & $24.71 \pm 2.22$ \\
\hline
\end{tabular}

Table 1: Demographic data of investigational subjects $(n=40)$.

chemistry (fasting glucose, liver function panel, creatinin, urea, uric acid, potassium, sodium, calcium, phosphorous, bicarbonate, lactic acid), urinalysis, were performed at screening (Day-21 to -1) and at study termination for safety purposes (Day 17). A 12-lead electrocardiogram and a chest $\mathrm{x}$-ray were also carried out at screening. For female with childbearing potential, serum pregnancy test was performed at screening and on urine samples previous to each dosing period. An abbreviated physical examination was carried out on the morning before drug administration. Vital signs (systolic and diastolic blood pressure in supine position and heart rate) were recorded during screening, immediately before drug administration, and 4,12 and $72 \mathrm{~h}$ after drug administration.

\section{Statistical analysis}

The following pharmacokinetic parameters: $\mathrm{C}_{\max }, \mathrm{AUC}_{\text {last }}$, and $\mathrm{AUC}_{\text {inf }}$ were analyzed for TFV and 3TC using natural log-transformed data. These PK variables were compared by means of ANOVA for a 2-treatment crossover design. The model included the fixed effects of period, sequence, and treatment. In accordance with scientific standards and international guidelines for bioequivalence studies, bioequivalence was concluded if the $90 \%$ confidence interval (CI) for the ratio of the geometric least-squares means (test treatment/reference treatment) was within the bounds of $80 \%$ to $125 \%$ for the primary PK parameters. All statistical tests used a $5 \%$ level of significance $[11,15]$.

\section{Results}

A total of 40 healthy subjects were enrolled in the study. All subjects were Caucasian, being 65\% (26/40) male and 35\% (14/40) female. Demographic data and mean health parameters of all the participants are summarized in Table 1. One subject was excluded from the study because of personal reasons after the first period of dosing.

\section{Pharmacokinetics}

The data set for TFV and 3TC analysis included 39 subjects. Figure 2 (arithmetic scale) and Figure 3 (semi log-transformed scale) show mean plasma concentration-time curves after single dose administration of 300/300 mg (TDF/3TC) of test and reference products. The mean curves for the two treatments for TFV and 3TC followed a typical profile for a conventional immediate release formulation and were almost superimposable. Elimination phase for both TFV and 3TC showed a biphasic shape (alpha and beta elimination half-lives) on both the test and reference products. Table 2 shows a comparison of individual subject $\mathrm{AUC}_{\text {last }}$ values for TFV/3TC test and reference treatments. For TFV 6 out of 39 subjects showed test $\mathrm{AUC}_{\text {last }}$ values $30 \%$ different to reference $\mathrm{AUC}_{\text {last }}$ data. In the case of $3 \mathrm{TC}$, individual $\mathrm{AUC}_{\text {last }}$ values differences between test and reference did not exceed $30 \%$ in none subjects, suggesting that extend of absorption was similar for both drugs. Plasma pharmacokinetic parameters for TFV and 3TC are summarized in Table 3. No statistical differences were observed between mean pharmacokinetic parameters for TFV and 3TC test and reference formulations. 

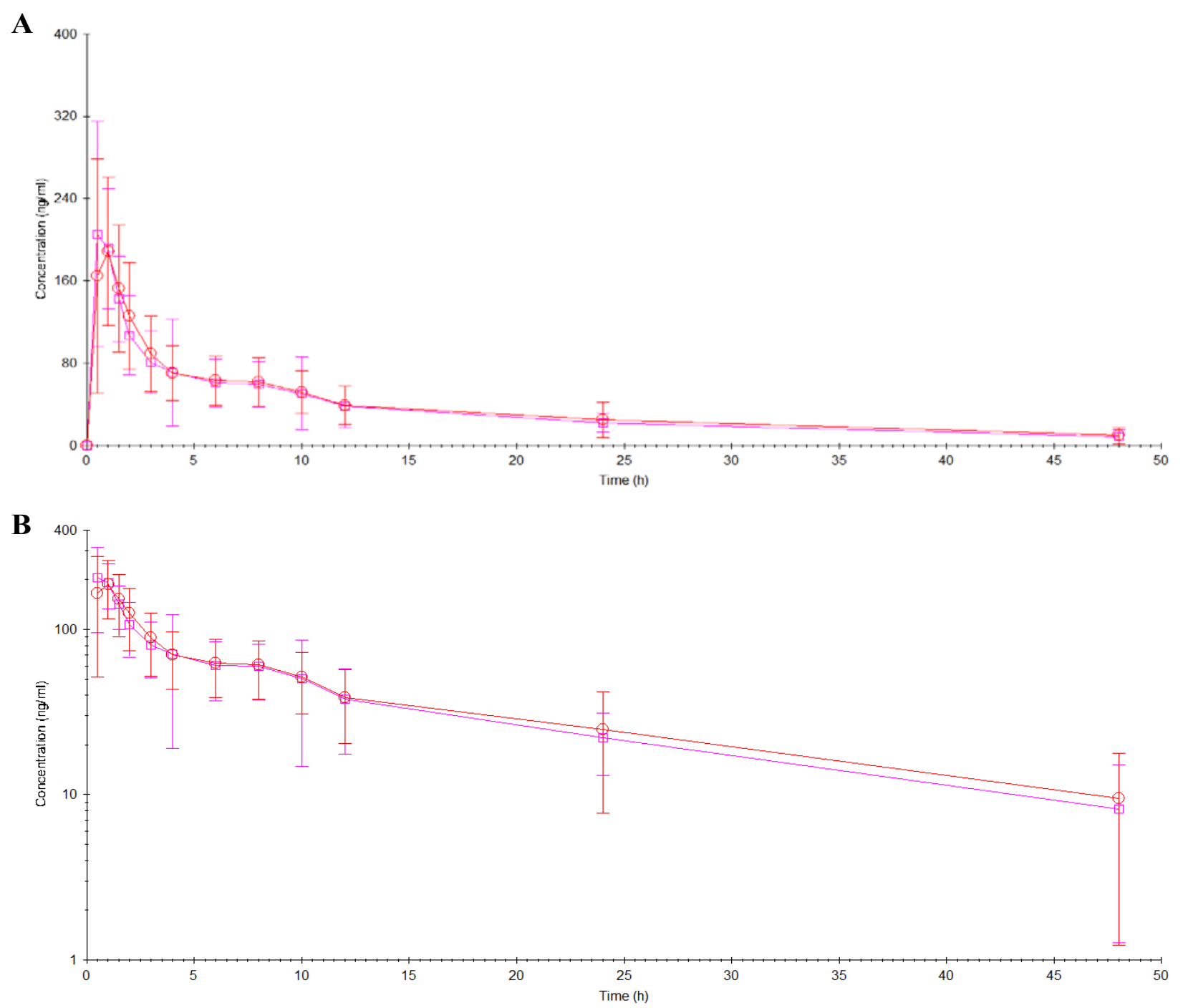

Figure 2: (A) Mean plasma concentration-time curves for TFV ( $n=39)$ following single-dose administration of test and reference $(1 \times 300 \mathrm{mg})$ tablets. Test= square and reference=circles.

(B) Mean plasma log-concentration time curves for TFV $(n=39)$ following single-dose administration of test and reference $(1 \times 300 \mathrm{mg})$ tablets. Test= square and reference=circles.

The analysis of variance did not show any statistically significant difference between test and reference formulations $(\mathrm{p}<0.05)$ in relation to the fixed effect of period, sequence and treatment for the pharmacokinetic parameters analyzed: $\ln \mathrm{C}_{\max }, \mathrm{AUC}_{\text {last }}$ and $\mathrm{AUC}_{\mathrm{inf}}$.

Statistical analysis of TFV and 3TC pharmacokinetic logtransformed parameters and their geometric least squares mean ratios for the test and reference treatment are presented in Tables 4 and 5 for TFV and 3TC formulations, respectively. The limits of the $90 \%$ confidence intervals (CI) for the ratios of $\mathrm{C}_{\text {max }}, \mathrm{AUC}_{\text {last }}$ and $\mathrm{AUC}_{\text {inf }}$ for their log-transformed data fell well within 80 to $125 \%$. Coefficients of intra-subject variation for $\mathrm{C}_{\max }, \mathrm{AUC}_{\text {last }}$ and $\mathrm{AUC}_{\text {inf }}$ corresponding to TFV were $0.23,0.40$ and 0.38 , respectively; and corresponding to $3 \mathrm{TC}$ were $0.25,0.20$ and 0.21 , respectively.

Test-Reference ratio for the geometric means (\%) for all primary pharmacokinetic metrics $\left(\mathrm{AUC}_{\text {last }}, \mathrm{AUC}_{\text {inf }}, \mathrm{C}_{\max }\right)$ and the corresponding $90 \%$ confidence intervals corresponding to TFV and 3TC were contained within the bioequivalence bounds of $80 \%$ to $125 \%$. Moreover, the null hypothesis of the two one-sided t-test Schuirmann could be rejected $(\mathrm{p}<0.05)$ as shown in Tables 4 and 5. Power of the statistical tests were much higher than 0.80 , as requested by regulatory agencies.

\section{Safety}

TFV was well tolerated by all subjects. No clinically significant changes in vital signs (blood pressure, heart rate) and safety laboratory tests were observed after single oral dose administration of TDF/3TC $300 / 300 \mathrm{mg}$. A total of 4 non-serious adverse events (AEs) which were considered not related to the study drug by the investigators were reported: One case of teeth ache of moderate intensity that resolved with the use of ibuprofen $400 \mathrm{mg}$, one case of pharyngitis of moderate intensity which resolved spontaneously, one case of skin injury and another case of traumatism in right knee of moderate intensity that resolved with local treatment. 
Citation: Feleder EC, Yerino GA, Halabe EK, Carla S, Soledad G, et al. (2011) Single-Dose Bioequivalence of a New Fixed-Dose Combination Tablet Containing Tenofovir Disoproxil Fumarate and Lamivudine. J Bioequiv Availab 3: 236-243. doi:10.4172/jbb.1000093

A

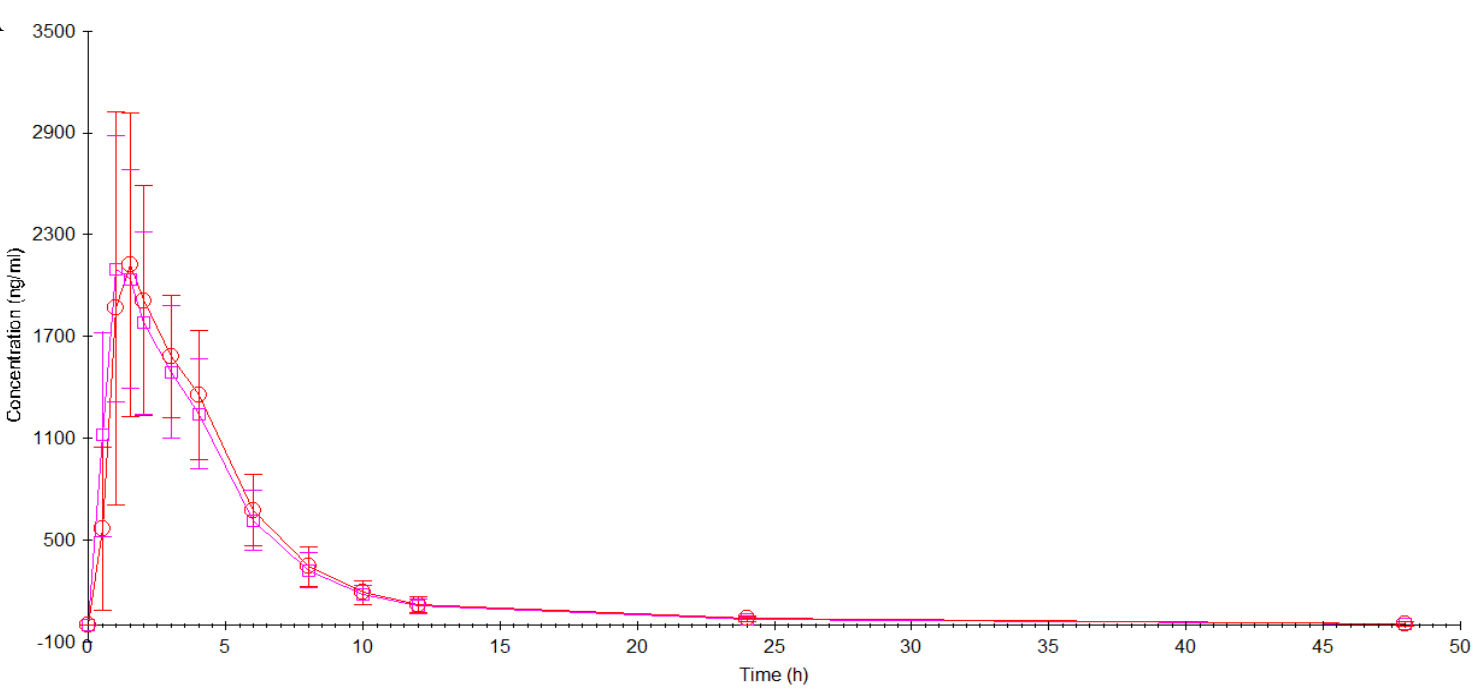

B

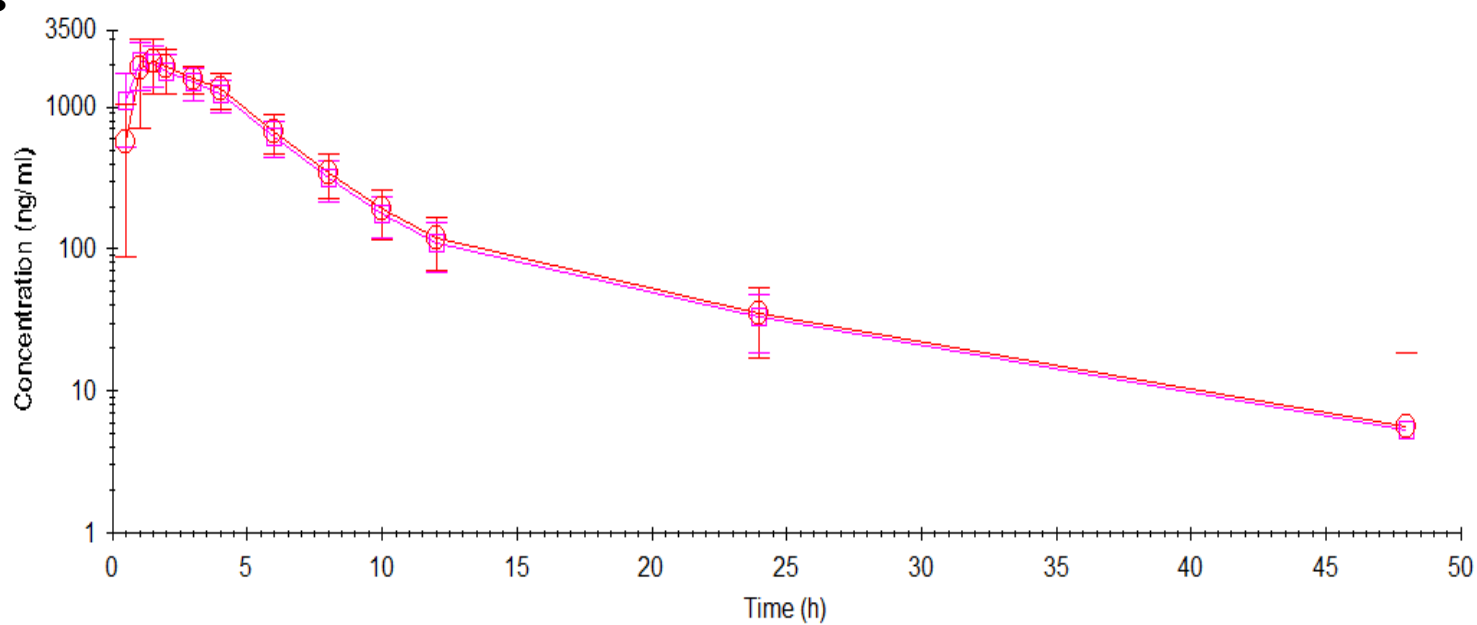

Figure 3: (A) Mean plasma concentration-time curves for 3 TC $(n=39)$ following single-dose administration of test $(1 \times 300 \mathrm{mg})$ and reference $(2 \times 150 \mathrm{mg})$ tablets. Test= square and reference $=$ circles.

(B) Mean plasma log-concentration time curves for 3TC $(n=39)$ following single-dose administration of test $(1 \times 300 \mathrm{mg})$ and reference $(2 \times 150 \mathrm{mg})$ tablets. Test= square and reference $=$ circles .

\begin{tabular}{|c|c|c|c|c|}
\hline \multirow{2}{*}{ Subject $N^{\circ}$} & \multicolumn{2}{|c|}{$\begin{array}{l}\text { Tenofovir }(\mathrm{N}=39) \\
\text { AUClast }\left(\mathrm{ng}^{*} \mathrm{~h} / \mathrm{ml}\right)\end{array}$} & \multicolumn{2}{|c|}{$\begin{array}{l}\text { Lamivudine }(\mathrm{N}=39) \\
\text { AUClast }\left(\mathrm{ng}^{*} \mathrm{~h} / \mathrm{ml}\right)\end{array}$} \\
\hline & Reference & Test & Reference & Test \\
\hline 1 & 2327.3 & 2430.14 & 18327.9 & 16637.88 \\
\hline 2 & 768 & 871.75 & 6953.47 & 8606.69 \\
\hline 3 & 1491.65 & 1685.77 & 14047.93 & 14361.01 \\
\hline 4 & 992.51 & 1369.27 & 10314.07 & 9830.74 \\
\hline 5 & 1220.5 & 1085.97 & 11113.99 & 8054.3 \\
\hline 6 & 1120.45 & 1452.77 & 11681.65 & 10481.75 \\
\hline 7 & 1915.7 & 2000.04 & 12317.39 & 14065.32 \\
\hline 8 & 1961.56 & 1217.3 & 9576.35 & 7036.73 \\
\hline 9 & 1748.94 & 1807.27 & 14461.87 & 13880.45 \\
\hline 10 & 1549.15 & 1261.47 & 5710.25 & 6333.19 \\
\hline
\end{tabular}


Citation: Feleder EC, Yerino GA, Halabe EK, Carla S, Soledad G, et al. (2011) Single-Dose Bioequivalence of a New Fixed-Dose Combination Tablet Containing Tenofovir Disoproxil Fumarate and Lamivudine. J Bioequiv Availab 3: 236-243. doi:10.4172/jbb.1000093

\begin{tabular}{|c|c|c|c|c|}
\hline 11 & 852.61 & 1565.02 & 9173.39 & 10023.46 \\
\hline 12 & 2043.18 & 2205.03 & 11780.66 & 9885.28 \\
\hline 13 & 1637.25 & 1527.86 & 13434.67 & 11200.56 \\
\hline 14 & 4842.91 & 4378.79 & 16641.18 & 14853.9 \\
\hline 15 & 2275.9 & 2210.23 & 7122.95 & 5826.2 \\
\hline 16 & 2000.89 & 1782.21 & 12072.39 & 11685.83 \\
\hline 17 & 1410.7 & 1440.59 & 12786.89 & 15643.27 \\
\hline 18 & 2050.43 & 1379.81 & 12828.37 & 11057.92 \\
\hline 19 & 1342.33 & 966.45 & 12744.42 & 9208.99 \\
\hline 20 & 1708.38 & 1535.18 & 11241.37 & 11558.16 \\
\hline 21 & 839.62 & 1011.15 & 12170.92 & 11068.7 \\
\hline 22 & 1053.88 & 927.19 & 10133.73 & 9764.9 \\
\hline 23 & 2350.86 & 1982.18 & 11690.22 & 10876.13 \\
\hline 24 & 1731.35 & 1545.3 & 10770.84 & 9867.83 \\
\hline 25 & 2820.83 & 2018.06 & 9633.14 & 12070.42 \\
\hline 26 & 2393.57 & 1585.59 & 10711.17 & 13438.01 \\
\hline 27 & 969.48 & 1066.34 & 10250.17 & 11075.47 \\
\hline 28 & 1238.2 & 1409.28 & 9335.52 & 10121.85 \\
\hline 29 & 2995.48 & 2914.91 & 8772.56 & 10643.76 \\
\hline 30 & 1684.65 & 1809.6 & 11422.97 & 11738.11 \\
\hline 31 & 796.34 & 889.81 & 10766.06 & 8849.27 \\
\hline 32 & 1960.62 & 1886.91 & 9763.98 & 9499.89 \\
\hline 33 & 1400.22 & 1739.67 & 9282.27 & 9858.01 \\
\hline 34 & 2121.61 & 2211.32 & 10685.38 & 10816.44 \\
\hline 35 & 1611.14 & 1173.49 & 9859.52 & 9652.06 \\
\hline 37 & 1819.93 & 1705.63 & 8703.72 & 9021.52 \\
\hline 38 & 1090.51 & 554.46 & 9922.89 & 8733.43 \\
\hline 39 & 731.41 & 714.04 & 8885.62 & 8193.66 \\
\hline 40 & 631.69 & 788.5 & 10144.54 & 9750.24 \\
\hline
\end{tabular}

Table 2: Individual subject AUClast values for TFV/3TC $(n=39)$ of either test or reference treatment.

\begin{tabular}{|c|c|c|c|c|c|c|}
\hline \multirow[b]{2}{*}{ PK Parameter } & \multicolumn{3}{|c|}{ Tenofovir $(\mathrm{N}=39)$} & \multicolumn{3}{|c|}{ Lamivudine ( $\mathrm{N}=39$ ) } \\
\hline & $\begin{array}{l}\text { Reference } \\
\text { arithmetic mean } \\
\text { (SD) }\end{array}$ & $\begin{array}{l}\text { Test } \\
\text { arithmetic mean } \\
\text { (SD) }\end{array}$ & $P$ value & $\begin{array}{l}\text { Reference } \\
\text { arithmetic } \\
\text { mean (SD) }\end{array}$ & $\begin{array}{c}\text { Test } \\
\text { arithmetic } \\
\text { mean (SD) }\end{array}$ & $P$ value \\
\hline$C_{\max }(\mathrm{ng} / \mathrm{ml})$ & $235.21(68.66)$ & $239.75(81.07)$ & 0.79 & $2538.80(964.98)$ & $2279.01(756.76)$ & 0.190 \\
\hline$T_{\max }$ (hours) & $0.95(0.55)$ & $0.77(0.32)$ & NA & $1.73(0.69)$ & $1.41(0.55)$ & NA \\
\hline $\mathrm{AUC}_{\text {last }}\left(\mathrm{ng}^{*} \mathrm{~h} / \mathrm{ml}\right)$ & $1679.53(783.72)$ & $1592.46(686.98)$ & 0.603 & $10954.77(2417.68)$ & 10647.98 (2399.37) & 0.575 \\
\hline $\mathrm{AUC}_{\mathrm{inf}}\left(\mathrm{ng}^{\star} \mathrm{h} / \mathrm{ml}\right)$ & 2043.68 (944.63) & 1894.78 (783.35) & 0.451 & 11300.91 (2585.9) & $10979.83(2543.85)$ & 0.582 \\
\hline$K_{e}(1 / h)$ & $0.05(0.02)$ & $0.05(0.02)$ & 1.00 & $0.13(0.08)$ & $0.14(0.07)$ & 0.558 \\
\hline Terminal half-life (h) & $17.07(7.20)$ & $16.42(6.70)$ & 0.681 & $6.99(4.12)$ & $6.33(3.49)$ & 0.447 \\
\hline
\end{tabular}

Table 3: Pharmacokinetic parameters of TFV/3TC in healthy volunteers $(n=39)$ following single-oral dose administration of either test or reference treatment. 
Citation: Feleder EC, Yerino GA, Halabe EK, Carla S, Soledad G, et al. (2011) Single-Dose Bioequivalence of a New Fixed-Dose Combination Tablet Containing Tenofovir Disoproxil Fumarate and Lamivudine. J Bioequiv Availab 3: 236-243. doi:10.4172/jbb.1000093

\begin{tabular}{|l|c|c|c|c|c|}
\hline \multicolumn{1}{|c|}{$\begin{array}{c}\text { Pharmacokinetic } \\
\text { Parameter }\end{array}$} & Ref GeoLMS(*) & Test GeoLMS(*) & $\begin{array}{c}\text { Ratio } \\
\text { (\% Ref) }\end{array}$ & $\begin{array}{c}\text { Classical } \\
\mathbf{9 0 \%} \text { Cl }\end{array}$ & $\begin{array}{c}\text { Two one-Sided t-test } \\
\text { Schuirmann }\end{array}$ \\
\hline LnC $_{\text {max }}$ (ng/ml) & 225.21 & 227.22 & 100.99 & $92.89-109.80$ & $\begin{array}{l}P(0<80 \%)=0.0000 \\
P(0>125 \%)=0.0001\end{array}$ \\
\hline LnAUC $_{\text {last }}$ (ng*h/ml) & 1528.89 & 1470.23 & 96.11 & $90.02-102.63$ & $\begin{array}{l}P(0<80 \%)=0.0000 \\
P(0>125 \%)=0.0000\end{array}$ \\
\hline LnAUC $_{\text {inf }}$ (ng*h/ml) & 1859.83 & 1763.12 & 94.73 & $88.22-101.73$ & $\begin{array}{l}P(0<80 \%)=0.0001 \\
P(0>125 \%)=0.0000\end{array}$ \\
\hline
\end{tabular}

(*) Geo LSM= Geometric Least Squares Mean

Table 4: Bioequivalence analysis for TFV following single-oral dose administration of either test ( $1 \times 300$ mg tablet) or reference treatment ( 1 x 300 mg tablet)

\begin{tabular}{|l|c|c|c|c|c|c|}
\hline \multicolumn{1}{|c|}{$\begin{array}{c}\text { Pharmacokinetic } \\
\text { Parameter }\end{array}$} & Ref GeoLMS(*) & Test GeoLMS(*) & $\begin{array}{c}\text { Ratio } \\
\text { (\% Ref) }\end{array}$ & $\begin{array}{c}\text { Classical } \\
\mathbf{9 0 \%} \text { Cl }\end{array}$ & $\begin{array}{c}\text { Two one-Sided t-test } \\
\text { Schuirmann }\end{array}$ & $\begin{array}{l}\mathrm{P}(0<80 \%)=0.0051 \\
\mathrm{P}(0>125 \%)=0.0000\end{array}$ \\
\hline LnC $_{\text {max }}$ (ng/ml) & 2399.36 & 2167.62 & 90.37 & $83.76-97.50$ & $\begin{array}{l}\mathrm{P}(0<80 \%)=0.0000 \\
\mathrm{P}(0>125 \%)=0.0000\end{array}$ \\
\hline LnAUC $_{\text {last }}$ (ng*h/ml) & 10700.50 & 10387.45 & 97.02 & $93.27-100.93$ & $\begin{array}{l}\mathrm{P}(0<80 \%)=0.0000 \\
\mathrm{P}(0>125 \%)=0.0000\end{array}$ \\
\hline LnAUC $_{\text {inf }}$ (ng*h/ml) & 11025.27 & 10704.50 & 97.04 & $93.41-100.82$ & 1.00 \\
\hline
\end{tabular}

(*) Geo LSM= Reference Geometric Least Squares Mean

Table 5: Bioequivalence analysis for 3TC following single-oral dose administration of either test ( $1 \times 300 \mathrm{mg}$ tablet) or reference treatment ( $2 \times 150 \mathrm{mg}$ tablet).

\section{Discussion}

The objective of the present study was to evaluate and compare the rate and extent of absorption of a new pharmaceutical oral equivalent tablet formulation containing a fixed dose combination of TDF/3TC $300 / 300 \mathrm{mg}$ to that from the same dose of the separate innovators formulations in healthy volunteers; and secondarily to assess bioequivalence between them.

Our results showed that no significance differences were found, in terms of rate and extent of absorption, between test and reference products, as indicated by $\mathrm{C}_{\max }$ and AUC comparisons and also by the similar plasma tenofovir and lamivudine concentration-time curves. Considering that $90 \%$ CIs of the ratios of $\mu \mathrm{T} / \mu \mathrm{R}$ for the PK parameters $\left(\mathrm{C}_{\max }\right.$ and $\mathrm{AUC}_{\mathrm{s}} \log$-transformed) were found to be within the predetermined range $(80 \%-125 \%)$ and the Schuirmann two onesided $t$ test procedure (probability of exceeding limits of acceptance) found all probability values $<0.05$, the null hypothesis that the estimated parameters exceeded limits of acceptance was rejected, both combination regimen tested were found to be bioequivalent.

This is the first study showing single-dose bioequivalence between a new fixed-dose combination tablet formulation of TDF/3TC 300/300 $\mathrm{mg}$ versus the regular single tablet regimen of TDF and 3TC in different dosage forms. The fact that the new dosage form, formulated as a combination tablet, was developed as a pharmaceutical equivalent product related to each innovator reference respectively, with similar pharmaceutical behavior, as seen by similar In vitro dissolution profiles, lead to obtain similar pharmacokinetic profiles and similar pharmacokinetic endpoints values In vivo.

The pharmacokinetic profile of TFV described in our study were lower than previous pharmacokinetic studies carried out in HIVinfected adults with mean calculated $\mathrm{AUC}_{\text {last }}$ values of: $2093 \mathrm{ng} \mathrm{h} / \mathrm{ml}$ [5], $3000 \mathrm{ng}^{\star} \mathrm{h} / \mathrm{ml}$ [6], $2290 \mathrm{ng}^{\star} \mathrm{h} / \mathrm{ml}$ [1]. In a previous single-dose, crossover, two-treatment bioequivalence study of a triple-combination tablet containing tenofovir disoproxil fumarate $(300 \mathrm{mg})$ in association with Efavirenz (600mg) and Emtricitabine $(200 \mathrm{mg}$ ) carried out in 45 healthy volunteers under fasting conditions, mean calculated TFV $\mathrm{AUC}_{\text {last }}$ from test and reference products reported were $1950 \mathrm{ng}^{\star} \mathrm{h} /$ $\mathrm{ml}$ and $1970 \mathrm{ng}{ }^{\star} \mathrm{h} / \mathrm{ml}$, respectively, being slightly higher than mean

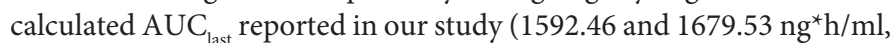
test and reference, respectively) [16]. This results could be explained by the inter individual variability of tenofovir pharmacokinetics which is quite large, being the sources of variability incompletely understood $[1,5,6]$.

Pharmacokinetic parameters of 3TC reported in our study were slightly higher than a previous randomized, two-way, crossover study carried out in 60 healthy volunteers comparing the steady-state of pharmacokinetics of lamivudine following 7 days of treatment with lamivudine at $300 \mathrm{mg}$ once daily versus the standard regimen of $150 \mathrm{mg}$ twice daily where the mean steady-state $\mathrm{C}_{\max }$ and AUC24h were 2040 $\mathrm{ng} / \mathrm{ml}$ and $8870 \mathrm{ng}{ }^{\star} \mathrm{h} / \mathrm{ml}$, respectively, at a therapeutic dose of $300 \mathrm{mg}$ once daily [17]. In another study comparing steady-state of lamivudine once daily $300 \mathrm{mg}$ versus twice daily $150 \mathrm{mg}$ in HIV-infected patients as part of HAART therapy for at least three months, mean $\mathrm{C}_{\max }$ and AUC24h reported values for $300 \mathrm{mg}$ once daily were $2230 \mathrm{ng} / \mathrm{ml}$ and $11800 \mathrm{ng}^{\star} \mathrm{h} / \mathrm{ml}$ which did not differ much from our data [18]. The differences in the PK parameters of 3TC obtained in our study could be explained by the interindividual variability of lamivudine $[7,8]$. In our study, mean calculated $3 \mathrm{TC} \mathrm{AUC}_{\text {last }}$ from test and reference formulations were higher than previously described mean values in HVB-infected patients $\left(4300 \pm 1400 \mathrm{ng} / \mathrm{ml}, \mathrm{AUC}_{\text {last }}\right.$ and $1280 \pm 560$ $\left.\mathrm{ng}{ }^{\star} \mathrm{h} / \mathrm{ml}\right)$. These results could be related to the lower dose $(100 \mathrm{mg})$ of 3TC used in this previous study and also to the inter individual variability of lamivudine [8].

Mean TFV half-life values for TFV and 3TC test and reference formulations, did not differ from previous reported data $[1,2,8,9]$.

In a previous pharmacokinetic study carried out in healthy volunteers, the most common adverse events reported during treatment with TFV were gastrointestinal disorders, fatigue, headache, somnolence and dizziness $[1,2,16]$. Common adverse events during therapy with lamivudine are malaise and fatigue, gastrointestinal disorders, headache, myalgia, and skin rashes [9]. However, in our study, no adverse events related to the study drug were observed.

The combination of TDF with 3TC as part of an EFV-based 
Citation: Feleder EC, Yerino GA, Halabe EK, Carla S, Soledad G, et al. (2011) Single-Dose Bioequivalence of a New Fixed-Dose Combination Tablet Containing Tenofovir Disoproxil Fumarate and Lamivudine. J Bioequiv Availab 3: 236-243. doi:10.4172/jbb.1000093

regimen in ART-naïve patients has better virologic responses than with zidovudine/lamivudine or with abacavir/lamivudine regimens in patients with baseline HIV RNA > 100,000 copies/mL and are associated with a less frequency of adverse events. The working group of the OARAC recommends in the last guidance the use of dual NRTIs (TDF + 3TC) in combination with a NNRTI, a PI (usually boosted with RTV), or an INSTI (integrase strand transfer inhibitor) as preferred regimens (AI) for antiretroviral therapy-naïve patients infected with $\mathrm{HIV}$, and the combination of TDF $+3 \mathrm{TC}$ or FTC as the preferred regimen (AII) for the treatment of HIV-HVB co-infected patients. The fixed-dose combination of TDF/3TC 300/300mg has the advantage to be administered as once daily tablet with or without food and leading to an improvement of treatment adherence, as it has been demonstrated with other fixed-dose combinations of TDF/FTC and TDF/FTC/EFV co-formulated recently [3].

In conclusion, the $90 \%$ confidence interval on the geometric mean test-to-reference $\mathrm{C}_{\text {max }}, \mathrm{AUC}_{\text {last }}$ and $\mathrm{AUC}_{\text {inf }}$ ratios were within the bioequivalence interval 80-125\% for both TDF and 3TC.

No statistically significant differences were found for fixed effects when ANOVA test was applied to the $\ln \mathrm{C}_{\max }, \mathrm{AUC}_{\text {last }}$ and $\mathrm{AUC}_{\text {inf }}$ Both formulations were similar in terms of rate and extent of absorption. This study demonstrated that the new pharmaceutical equivalent fixed-dose combination of TDF/3TC $300 / 300 \mathrm{mg}$ in a single oral tablet formulation is also bioequivalent to the reference products as single-drug products. Then, considering that test product is pharmaceutical equivalent and bioequivalent implies that both products are therapeutically equivalent.

\section{Acknowledgments}

All authors thanks to Dr. Marcelo Befumo for bioanalytical methods development and validation and to Mr. Claudio A. Servente, Study Coordinator of the present study. All authors thanks to Richmond Laboratories, Buenos Aires, Argentina for the financial support.

\section{References}

1. Gilead Sciences, Inc. (2010) Product Monograph PrViread (Tenofovir Disoproxil Fumarate Tablets) $300 \mathrm{mg}$ Antiretroviral Agent.

2. Deeks SG, Braditch-Crovo PS, Lietman FH, Huang F, Cundy KC et al. (1998) Safety, pharmacokinetics, and antiretroviral activity of intravenous 9-[2- ${ }^{\circledR}$ (phosphonomethoxy) propyl] adenine, a novel anti-human immunodeficiency virus(HIV) therapy, in HIV-infected adults. Antimicrob Agents Chemother 42: 2380-2384.

3. Working Group of the Office of AIDS Research Advisory Council (OARAC) -Department of Health and Human Services (DHHS) (2011): Guidelines for the use of antiretroviral agents in HIV-1-infected adults and adolescents.

4. Hammer SM, Saag MS, Schechter M, Montaner JS, Schooley RT, et al. (2006) Treatment for adult HIV infection: 2006 recommendations of the International AIDS Society-USA panel. JAMA 296: 827-843.

5. Barditch-Crovo P, Deeks SG, Collier A, Safrin S, Coakley DF, et al. (2011) Phase I/II Trial of the Pharmacokinetics, Safety, and Antiretroviral Activity of Tenofovir Disoproxil Fumarate in Human Immunodeficiency Virus-Infected Adults.Antimicrob. Agents Chemother 46: 2733-2739.

6. Jullien V, Treluyer JM, Rey E, Jaffray P, Krivine A, et al. (2005) Population Pharmacokinetics of Tenofovir in Human Immunodeficiency Virus-Infected Patients Taking Highly Active Antirretroviral Therapy. Antimicrob. Agents Chemother 49: 3361-3366.

7. Kearney BP, Flaherty JF, Shah J (2004) Tenofovir Disoproxil Fumarate: Clinical Pharmacology and Pharmacokinetics. Clin Pharmacokinetic 43: 595-612.

8. Johnson MA, Moore KH, Yuen GJ, Bye A, Pakes GE (1999) Clinical Pharmacokinetics of Lamivudine. Clin Pharmacokinet.36: 41-66.
9. EMA-Scientific discussion for the approval of Epivir (lamivudine) tablets (2005)

10. U.S. Department of Health and Human Services, Food and drug Administration Center for Drug Evaluation and Research (CDER). (1996) ICH E6. Good Clinical Practices: Consolidated Guidance.

11. U.S. Department of Health and Human Services, Food and drug Administration Center for Drug Evaluation and Research (CDER) (2003) Guidance for Industry: Bioavailability and Bioequivalence Studies for orally Administered Drug Products - General Considerations. Revision 1. Rockville, MD

12. World Medical Association Declaration of Helsinki. Ethical Principles for Medical Research Involving Human Subjects. Seoul, 2008.

13. Marzo AL, Balant LP (1995) Bioequivalence: an updated reappraisal addresses to applications of interchangeable multi-source pharmaceutical products. Arzneimittelforschung 45: 109-115.

14. U.S. Department of Health and Human Services, Food and drug Administration Center for Drug Evaluation and Research (CDER) (2001) Guidance for Industry: Bioanalytical Method Validation.

15. European Agency for the Evaluation of Medicinal Products. Committee for Propietary Medicinal Products (CPMP) (2001) Note for Guidance on the Investigation of Bioavailability and Bioequivalence. CPMP/EWP/QWP/1401/98. London, UK.

16. Mathias AA, Hinkle J, Menning M, Hui J, Kaul S, Kearney BP, et al. (2007) Bioequivalence of Efavirenz/Emtricitabine/Tenofovir Disoproxil Fumarate Single-Tablet Regimen. J Acquir Immune Defic Syndr 46: 167-173.

17. Yuen GJ, Lou Y, Bumgarner NF, Bishop JP, Smith GA, et al. (2004) Equivalent Steady-State Pharmacokinetics of Lamivudine in Plasma and Lamivudine Triphosphate within Cells following Administration of Lamivudine at 300 Milligrams Once Daily and 150 Milligrams Twice Daily. Antimicrob Agents Chemother 48: 176-182.

18. Ye M, Wang L, Fu Q, Zhu Z, Li P, Li T (2010) Steady-state pharmacokinetics of lamivudine once-daily versus twice-daily dosing in Chinese HIV-infected patients. HIV Clin Trials 11: 230-237. 